\title{
Pelatihan Peningkatan Perpustakaan Sekolah sebagai Sumber Belajar bagi Lembaga Pendidikan NU Maarif Se Malang Raya
}

\author{
Moh Safii*1, Setiawan², Moch. Syahri ${ }^{3}$, Ahmad Munjin Nasih ${ }^{4}$ \\ ${ }^{123}$ Program Studi Ilmu Perpustakaan, Fakultas Sastra, Universitas Negeri Malang \\ 4Program Studi Pendidikan Bahasa Arab, Fakultas Sastra, Universitas Negeri Malang \\ *e-mail: moh.safii@um.ac.id¹ ${ }^{1}$, setiawan@um.ac.id², moch.syahri.fs@um.ac.id ${ }^{3}$,munjin.nasih.fs@um.ac.id ${ }^{4}$
}

\begin{abstract}
Realizing According to Law No. 43 of 2007 that every school operates a library that meets the national library standards by taking into account the National Library Standards. Libraries are required to have a collection of textbooks designated as compulsory textbooks in the education unit concerned in sufficient numbers to serve all students and educators. To make this happen, libraries must have competent human resources in their fields. The implementation method used is exposure/lecture, discussion and mentoring via WhatsApp group. The training was held in one day, starting with the pre-test and post-test. The training materials include Library Management, Classification and Cataloging and Library Automation. From the pre-test results, it was found that the category was very poor with an average score of 33 and an average post-test score of 92 with a very satisfying category. From the increase in the pre-test to post-test scores, it was found that this training was able to provide knowledge of school library management based on library automation.
\end{abstract}

Keywords: school library, library management, classification, library automation, digital library

\begin{abstract}
Abstrak
Mewujudkan Menurut UU No 43 Tahun 2007 bahwa setiap sekolah menyelenggarakan perpustakaan yang memenuhi standar nasional perpustakaan dengan memperhatikan Standar Nasional Perpustakaan. Perpustakaan wajib memiliki koleksi buku pelajaran yang ditetapkan sebagai buku teks wajib pada satuan pendidikan yang bersangkutan dalam jumlah yang mencukupi untuk melayani semua peserta didik dan pendidik. Untuk mewujudkan hal tersebut tentu perpustakaan harus memiliki sumber daya manusia yang kompeten dibidangnya. Metode Pelaksanaan yang digunakan ialah paparan/ceramah, diskusi dan pendampingan via grup whatsapp. Waktu pelatihan diselenggarakan sehari dengan dimulai pre-test dan post-test. Materi pelatihan meliputi Manajemen Perpustakaan, Klasifikasi dan Katalogisasi serta Otomasi Perpustakaan. Dari hasil pre-test didapatkan kategori sangat kurang dengan nilai rata-rata 33 dan nilai post-test rata-rata 92 dengan kategori sangat memuaskan. Dari peningkatan nilai pre-test ke post-test didapatkan bahwa pelatihan ini mampu memberikan pengetahuan pengelolaan perpustakaan sekolah berbasis otomasi perpustakaan.
\end{abstract}

Kata kunci: perpustakaan sekolah, manajemen perpustakaan, klasifikasi, otomasi perpustakaan, perpustakaan digital

\section{PENDAHULUAN}

Menurut UU No 43 Tahun 2007 bahwa setiap sekolah menyelenggarakan perpustakaan yang memenuhi standar nasional perpustakaan dengan memperhatikan Standar Nasional Perpustakaan. Perpustakaan wajib memiliki koleksi buku pelajaran yang ditetapkan sebagai buku teks wajib pada satuan pendidikan yang bersangkutan dalam jumlah yang mencukupi untuk melayani semua peserta didik dan pendidik (Vidiyawati, 2017). Untuk mewujudkan hal tersebut tentu perpustakaan harus memiliki sumber daya manusia yang kompeten dibidangnya (Andayani, 2018). Istilah orang yang bekerja di perpustakaan di Indonesia ada 2 yaitu pustakawan dan tenaga teknis perpustakaan sedangkan kualifikasinya sesuai dengan standar yang ada. Aturan ini tidak baku atau ketat masih bisa dirangkap menjadi 1 orang yang disebut single librarian (Maulida, 2019). Padahal kekurangan tenaga perpustakaan akan membuat pengelolaan perpustakaan tidak maksimal apalagi yang ditugaskan ialah guru yang sekaligus merangkap kepala perpustakaan. Sekarang kita lihat, ada berapa banyak pustakawan dan tenaga perpustakaan yang tercatat dalam database Perpustakaan Nasional Republik Indonesia. 
Tabel 1. Jumlah Pustakawan dan Tenaga Perpustakaan

\begin{tabular}{ll}
\hline Perpustakaan Sekolah (SD) & 503 \\
Perpustakaan Sekolah (SLTA) & 1572 \\
Perpustakaan Sekolah (SLTP) & 401 \\
\hline
\end{tabular}

Dari tabel 1 tentu ada perbandingan data yang mencengangkan, bahwa jumlah perpustakaan dan pustakawan tidak sebanding. Apabila dalam satu sekolah minimal terdapat satu pustakawan dan satu tenaga teknis perpustakaan, maka kebutuhan ideal pustakawan sebagai berikut.

Tabel 2. Potret Perpustakaan di Indonesia

\begin{tabular}{ccccc}
\hline Perpustakaan & Jumlah & $\begin{array}{c}\text { Jumlah } \\
\text { Pustakawan } \\
\text { Tercatat }\end{array}$ & $\begin{array}{c}\text { Kebutuhan } \\
\text { Ideal } \\
\text { Pustakawan }\end{array}$ & Kekurangan \\
\hline SD & 148.682 & 503 & 297.364 & 296.861 \\
SMP & 39.640 & 1.572 & 79.280 & 77.708 \\
SMA & 27.862 & 401 & 55.724 & 55.323 \\
\hline
\end{tabular}

Melihat tabel 2 diatas, tentu ada banyak sekali kekurangan tenaga perpustakaan dan dapat dibayangkan bagaimana keadaan perpustakaan di Indonesia. Sekarang kita lihat bagaimana data kondisi perpustakaan di Indonesia.

Tabel 3. Kondisi Perpustakaan Sekolah di Indonesia Tahun 2019

\begin{tabular}{ccccccc}
\hline Jenjang & Baik/Good & $\begin{array}{l}\text { Rusak Ringan } \\
\text { Minor } \\
\text { Damage }\end{array}$ & $\begin{array}{l}\text { Rusak Sedang } \\
\text { Middle } \\
\text { Damage }\end{array}$ & $\begin{array}{l}\text { Rusak Berat } \\
\text { Major } \\
\text { Damage }\end{array}$ & $\begin{array}{l}\text { Rusak Total } \\
\text { Totally } \\
\text { Damage }\end{array}$ & Jumlah \\
\hline SD & 30,096 & 53,959 & 5,698 & 4,814 & 3,770 & 98,337 \\
SMP & 9,681 & 15,570 & 2,169 & 2,159 & 1,491 & 31,070 \\
SMA & 9,736 & 10,153 & 799 & 683 & 509 & 21,880 \\
Jumlah & 49,513 & 79,682 & 806,867 & 689,973 & 514,261 & 117,754 \\
\hline
\end{tabular}

Potret diatas juga berlaku pada sekolah di Kota Malang. Dukungan positif dari pimpinan kepada pengelola perpustakaan sekolah biasanya terdapat pada sekolah negeri. Namun berbeda pada sekolah swasta apalagi sekolah di bawah Lembaga Pendidikan Maarif. Sangat sedikit kontribusi pimpinan terhadap pengembangan perpustakaan sekolah.

\section{PERMASALAHAN MITRA}

Dari hasil wawancara secara random dengan sekolah di bawah Lembaga Pendidikan Maarif dapat disimpulkan bahwa mereka memiliki kendala pada perpustakaan sebagai berikut :

1. Siswa disibukkan dengan jadwal pelajaran yang padat, sehingga hampir tidak ada waktu ke perpustakaan

2. Sarana dan prasarana tidak memadai termasuk didalamnya koleksi perpustakaan.

3. Kapabilitas/Kompetensi pustakawan dalam melayani yang tidak sesuai dengan yang dikehendaki

4. Siswa lebih memilih menggunakan internet untuk membaca dan mencari sumber rujukan.

5. Pustakawan tidak memiliki kemampuan di bidang teknis pengelolaan perpustakaan berbasis teknologi

6. Guru yang merangkap sebagai pustakawan menyebabkan kegiatan di perpustakaan tidak maksimal karena hanya diselesaikan disaat waktu luang. 
7. Secara teknis, tidak memiliki perangkat keras/server untuk dapat digunakan sebagai penyedia akses aplikasi perpustakaan digital

8. Tidak memiliki aplikasi/software perpustakaan digital

9. Perpustakaan masih dikelola secara manual

Data diatas berdasarkan observasi dan wawancara dengan pengelola Perpustakaan MTS 01 Maarif Singosari, Kabupaten Malang.

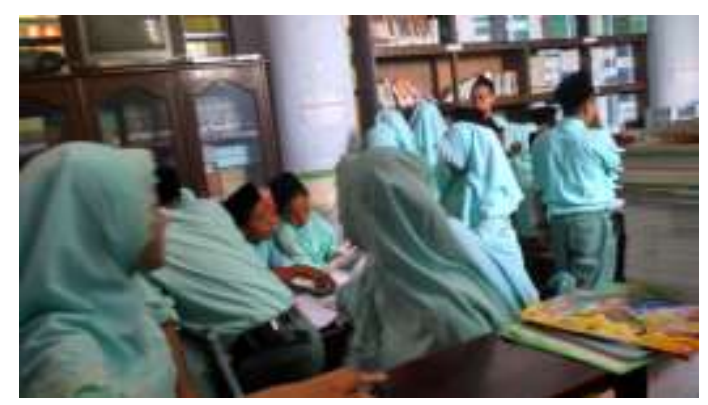

Gambar 1. Antusias Siswa

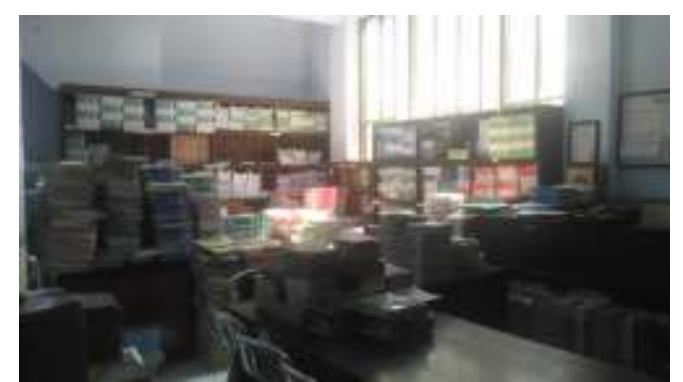

Gambar 2. Penataan Koleksi Perpustakaan

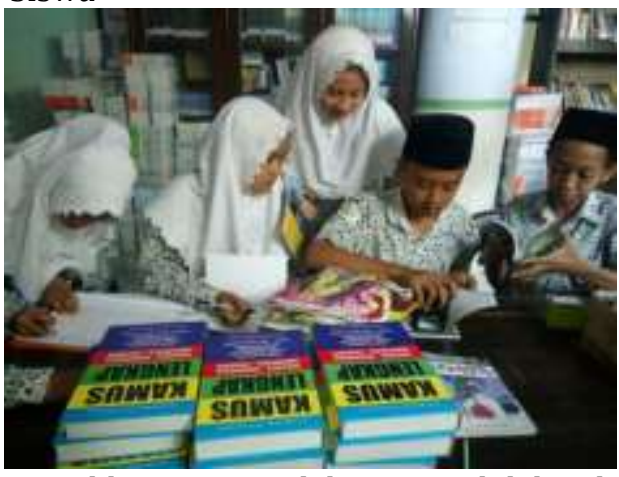

Gambar 3. Keterlibatan siswa dalam pengelolahan koleksi

Hasil Observasi dengan pengelola Perpustakaan SMP Wahid Hasyim Kota Malang, ditemukan pengelaan perpustakaan masih menggunakan cara manual.

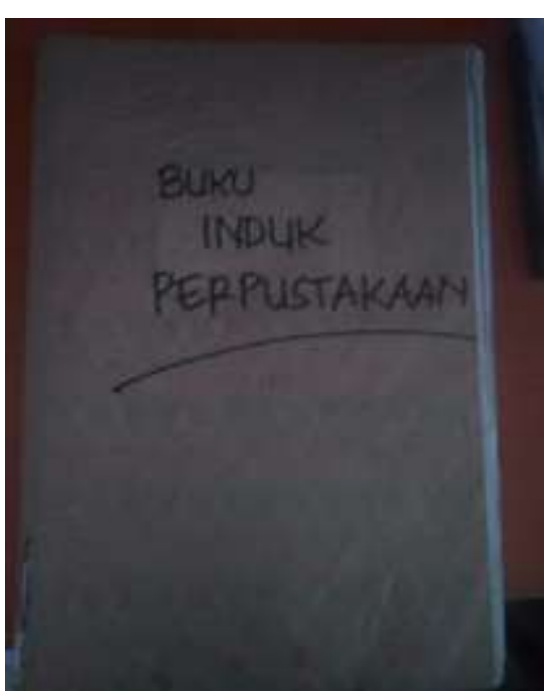

Gambar 4. Buku induk

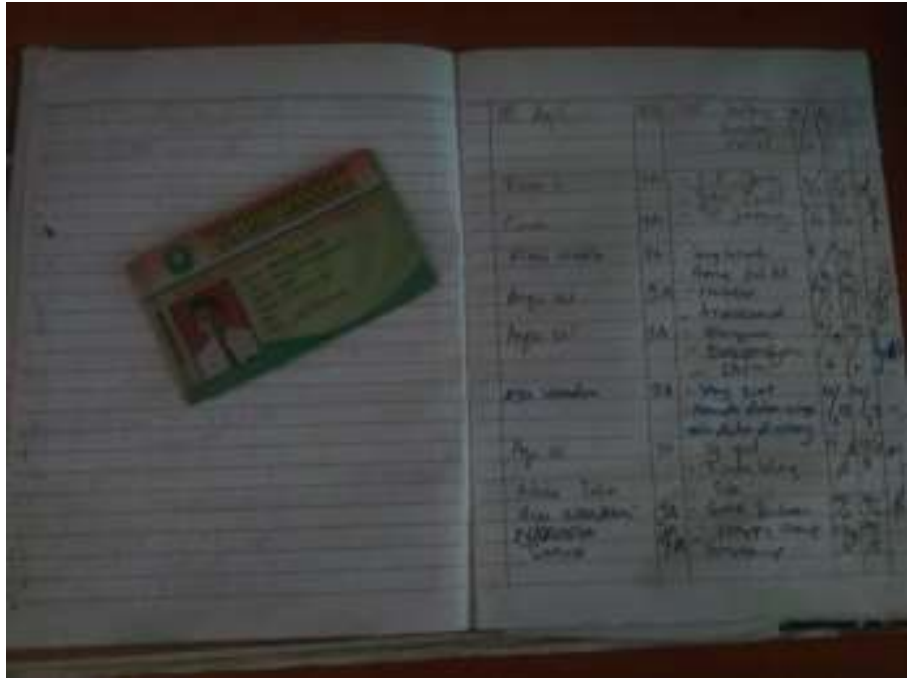

Gambar 5. Buku kunjungan siswa 


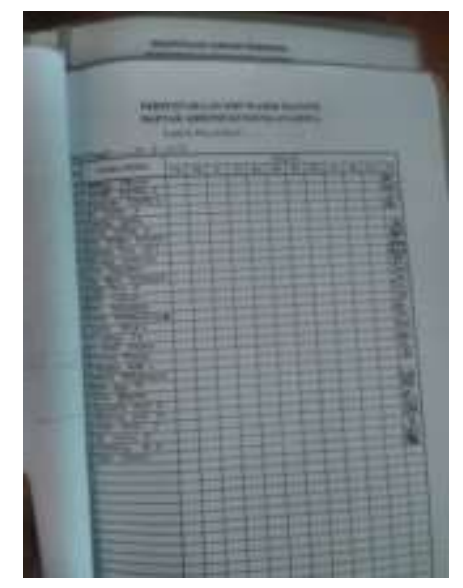

Gambar 6. Pencatatan kunjungan

\section{METODE}

Pengabdian ini melibatkan mitra yaitu LP Maarif Nahdlatul Ulama Kota Malang. Keterlibatan mitra diatur oleh Universitas Negeri Malang sebagai pemberi pendanaan pengabdian. LP Maarif menjadi mitra dikarenakan dari serangkaian kegiatan pengabdian yang telah diselenggarakan Prodi Ilmu Perpustakaan Universitas Negeri Malang, sekolah di bawah naungan LP Maarif belum pernah terlibat sama sekali. Mitra bertugas untuk mendata dan mengumpulkan sekolah di bawah naungan LP Maarif yang memiliki kriteria belum sama sekali mendapatkan pelatihan perpustakaan sekolah. Berdasar data dari LP Maarif tersebut, terkumpul 35 perwakilan sekolah. Kegiatan ini selain bekerjasama dengan mitra juga melibatkan mahasiswa Prodi Ilmu Perpustakaan sejumlah 10 mahasiswa untuk aktif mendampingi peserta. Kegiatan diselenggarakan pada tanggal 9 Agustus 2020, di Kantor PCNU Kota Malang dimulai pukul 07.30 - 15.00 WIB.

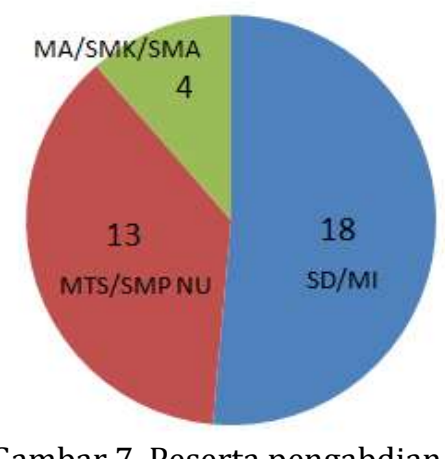

Gambar 7. Peserta pengabdian

Penilaian terhadap peserta pelatihan dilakukan menjelang pembukaan dalam bentuk :

a) Pre-test dilaksanakan setelah pembukaan sebelum materi pertama. Peserta diberikan link Google Form untuk kemudian diisi berdasarkan pengetahuan yang mereka miliki

b) Post-test dilaksanakan menjelang penutupan.

Menurut (Hairun, 2020) penentuan skor penilaian dapat dilakukan dengan menggunakan interval skor serta akan dikonversi ke dalam kualifikasi, seperti yang ditunjukkan pada tabel 4 berikut.

Tabel 4. Skor penilaian

\begin{tabular}{ll}
\hline Interval Skor & Kualifikasi \\
$81-100$ & Sangat Memuaskan \\
$71-80$ & Memuaskan \\
\hline
\end{tabular}




\begin{tabular}{ll}
\hline $61-70$ & Baik \\
$51-60$ & Cukup \\
$41-50$ & Kurang \\
$31-40$ & Sangat Kurang \\
$<30$ & Tidak Baik \\
\hline
\end{tabular}

Selama pelatihan pemateri menggali data kualitatif dari peserta terkait dengan pengelolaan perpustakaan sekolah. Data tersebut akan digunakan sebagai bahan diskusi terkait materi yang disampaikan.

\section{HASIL DAN PEMBAHASAN}

\subsection{Hasil}

Pengabdian kepada masyarakat ini diselenggarakan bekerjasama dengan LP Maarif Nahdlatul Ulama Kota Malang. Terdapat 35 peserta dari tingkat SD/MI, SMP/MTS dan SMA/SMK/MA se Malang Raya (Kota Batu, Kabupaten Malang dan Kota Malang). Pembukaan dibuka oleh perwakilan dari Lembaga Penelitian dan Pengembangan Masyarakat (LP2M) Universitas Negeri Malang diwakili oleh Sektretaris LP2M dan perwakilan LP Maarif oleh Ust Abdurrohim.

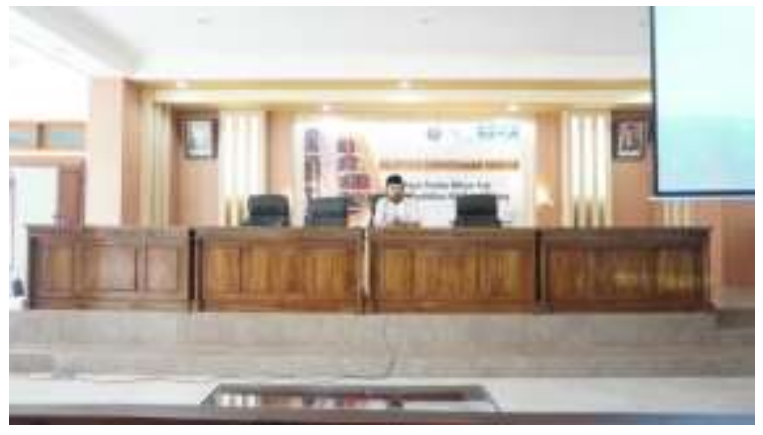

Gambar 8. Sambutan LP2M UM

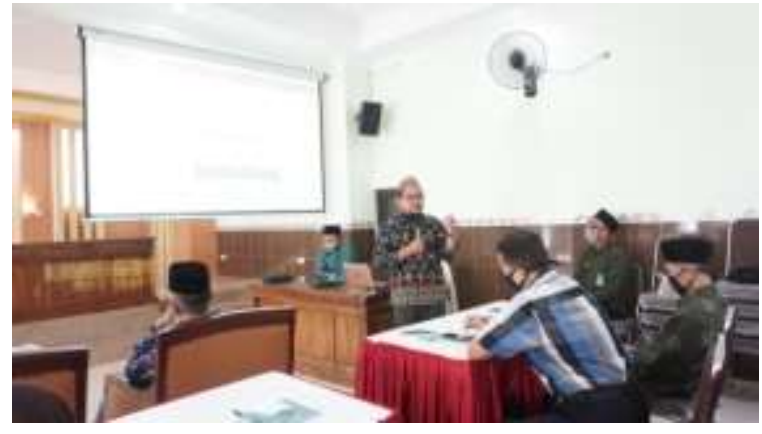

Gambar 9. Sambutan LP Maarif NU Kota Malang

Setelah pembukaan pre-test diberikan untuk mengukur pengetahuan dasar terkait materi yang akan diberikan. Materi pertama yaitu klasifikasi dan katalogisasi berisi tentang dasar-dasar pengolahan bahan koleksi perpustakaan. Materi ini merupakan bekal utama bagi peserta pelatihan agar dapat mengolah bahan pustaka sesuai dengan kaidah bidang perpustakaan. Pada materi pertama poin penting diberikan terkait katalogisasi, penentuan 9 daerah bidang ISBD, tajuk subyek, dan penentuan nomor klasifikasi. Untuk penentuan tajuk subyek diberikan Daftar Tajuk Subyek dari Perpustakaan Nasional, dan untuk penentuan nomor klasifikasi diberikan E-DDC 23.

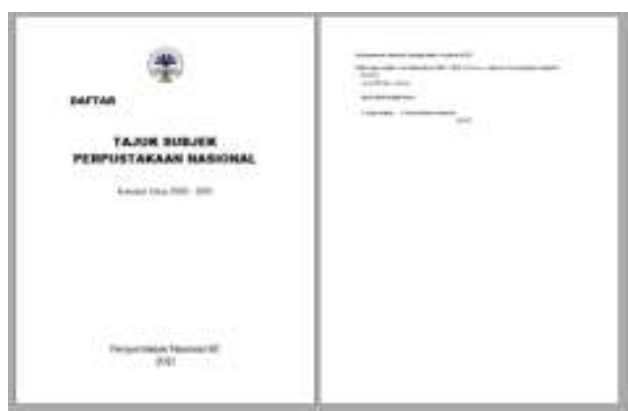

Gambar 10. Tajuk Subyek Perpustakaan Nasional dalam bentuk Ebook

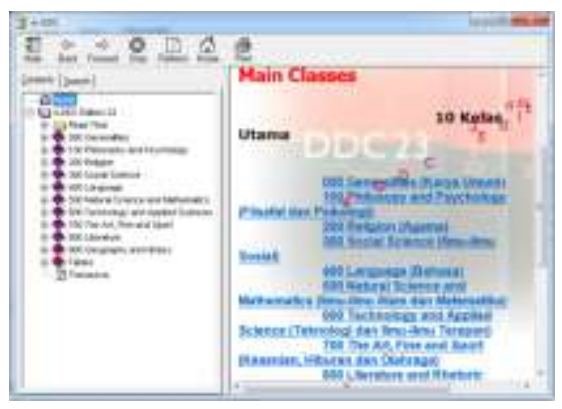

Gambar 11. E-DDC Versi 23 dalam bentuk aplikasi

Paparan materi pertama diakhiri dengan diskusi terkait klasifikasi koleksi, peserta diminta untuk menentukan nomor klasifikasi berdasarkan identitas buku yang diberikan. Materi 
selanjutnya ialah manajemen perpustakaan yang meliputi pengembangan koleksi dan evaluasi koleksi. Sebelum memulai materi kedua ini, digali pertanyaan kepada peserta menggunakan media menti. Pemateri kedua menanyakan kendala selama ini dalam mengelola perpustakaan. Peserta menyampaikan secara kualitatif dengan hasil sebagai berikut;

a) Tidak memiliki pemahaman tentang perpustakaan (bukan sarjana/diploma ilmu perpustakaan, baru ditugaskan sebagai pengelola perpustakaan)

b) Tidak ada ruangan perpustakaan (kalaupun ada ruangan tidak memadai)

c) Tidak ada koleksi buku yang memadai (didominasi buku pelajaran, tidak mengetahui prosedur pengadaan buku)

d) Masih manual belum ada otomasi perpustakaan

e) Minat baca siswa rendah

f) Sumberdaya yang terbatas (pustakawan dan dukungan fasilitas)

Atas dasar data kualitatif tersebut, pemateri membahas dan mengaitkan dengan teori dalam manajemen perpustakaan dan singgungan dengan materi otomasi perpustakaan. Dipaparkan juga terkait bagaimana perpustakaan meningkatkan minat baca siswa melalui kegiatan promosi dan inovasi dalam bentuk lain yang pada intinya untuk menarik lebih banyak lagi pemustaka agar memanfaatkan sumberdaya yang dimiliki perpustakaan sekolah secara maksimal (Nurhandini, 2020). Materi selanjutnya ialah otomasi perpustakaan. Otomasi perpustakaan sangat penting dan menjadi kunci dari pelatihan perpustakaan berbasis teknologi informasi. Otomasi perpustakaan dapat diartikan sebagai suatu upaya pengendalian proses/ kegiatan perpustakaan secara otomatis. Hal tersebut tidak terlepas dari pemanfaatan teknologi informasi di perpustakaan (library automation), terutama penggunaan teknologi komputer dan teknologi komunikasi (Loneli Costaner, Guntoro, \& Yuhelmi, 2020). Tujuan penting dari otomasi perpustakaan ialah;

a) Untuk memenuhi kebutuhan pemustaka tentang informasi secara lebih cepat, tepat dan akurat;

b) Untuk memenuhi kebutuhan pengelola perpustakaan dalam mengolah dan menyajikan koleksi, serta melayani pemustaka secara lebih efektif dan efisien;

c) Untuk memenuhi kebutuhan organisasi perpustakaan agar dapat tetap eksis dan mampu berkembang secara optimal serta memiliki daya saing tinggi dengan lembaga sejenis, baik di tingkat nasional maupun internasional.

Tujuan otomasi diatas menjadi solusi dari permasalahan peserta yang telah kami gali melalui media menti. Memberi kemudahan kepada pemustaka menjadi tujuan utama agar informasi yang dibutuhkan pemustaka dapat tersedia dengan cepat dan tepat (Nugraha, 2014). Pada materi terakhir ini peserta menggunakan laptop masing-masing dan menginstall aplikasi otomasi perpustakaan yaitu Senayan Library Management System (SLIMS) versi 9. Aplikasi yang diberikan kepada peserta telah diatur sedemikian rupa agar mudah untuk digunakan peserta. Pemateri telah membuat aplikasi tersebut secara portable sehingga tidak membutuhkan waktu yang lama untuk instalasi. Untuk memastikan bahwa aplikasi terinstall dengan tepat pada masing-masing laptop, mahasiswa mendampingi peserta sampai akhir.

SLIMS digunakan dalam penelitian ini dikarenakan aplikasi ini sesuai dengan kebutuhan pengelolaan perpustakaan. Di samping itu aplikasi tersebut telah sesuai dengan kaidah-kaidah bidang ilmu perpustakaan termasuk didalamnya kelengkapan cantuman, metadata dan juga kelengkapan house keeping library untuk pengelolaan perpustakaan secara menyeluruh (Puspitasari, 2016). 


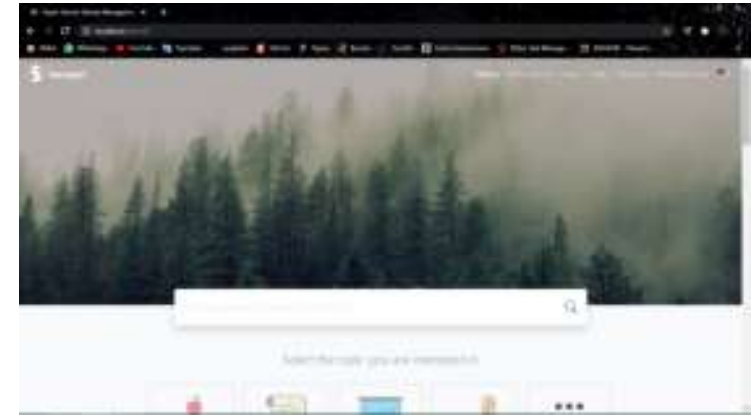

Gambar 12. Aplikasi SLIMS

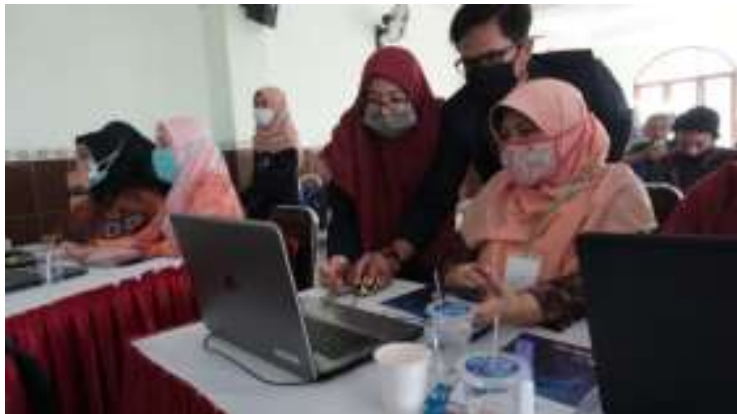

Gambar 13. Pendampingan oleh mahasiswa

Materi otomasi perpustakaan terdiri dari Entri bibliografi, pencetakan label, pencetakan barcode, entry anggota, cetak kartu anggota, peminjaman, pengembalian dan perpanjangan. Pemahaman tentang menu utama tersebut akan membantu pustakawan agar mampu bekerja dengan baik secara cepat dan tepat dibantu dengan aplikasi SLIMS. Setelah pelatihan maka pustakawan dapat menerapkan aplikasi ini untuk perpustakaan masing-masing. Sehingga nantinya penggunaan aplikasi tersebut akan menentukan inovasi pengelola perpustakaan selanjutnya tentu dengan dukungan lembaga (Henry Februariyanti, 2012).

Untuk memudahkan peserta dalam mendalami aplikasi ini, selain peserta mendapatkan powerpoint, juga mendapatkan tutorial penggunaan yang telah disiapkan sebelumnya. Akhir pelatihan ini panitia membuatkan grup whatsapp untuk pendampingan dan pengisian post-test. Secara ringkas alur selama pelatihan disajikan dalam gambar berikut;

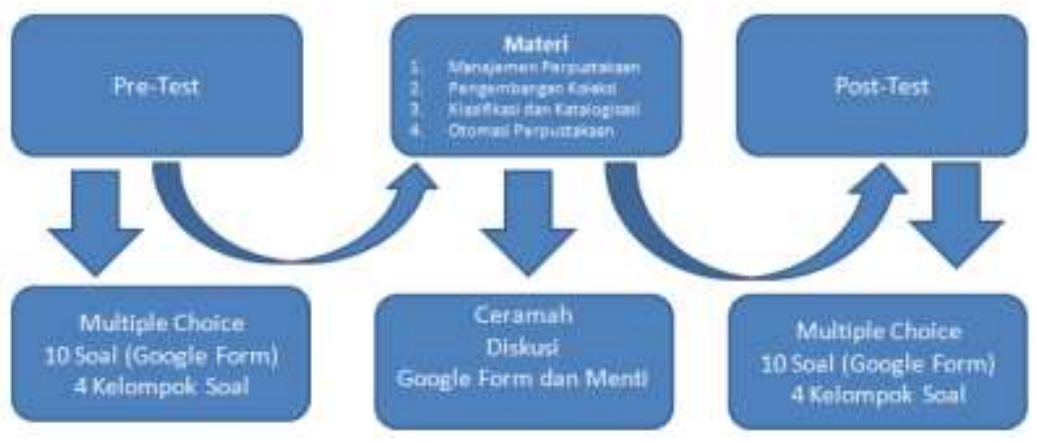

Gambar 14. Alur penyampaian materi

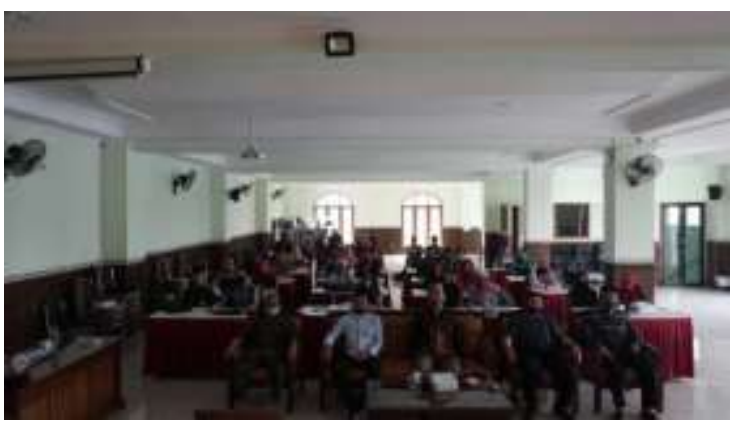

Gambar 15. Foto Peserta, Panitia dan Pemateri

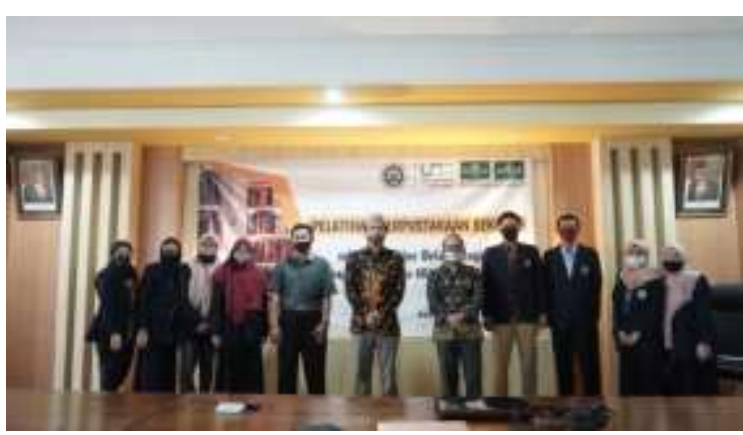

Gambar 16. Foto Pemateri dan Perwakilan LP Maarif

Kegiatan pengabdian kepada masyarakat ini dipublikasi juga pada media cetak dan online yaitu Radar Malang (web dan instagram) serta Malang Post (media cetak). 


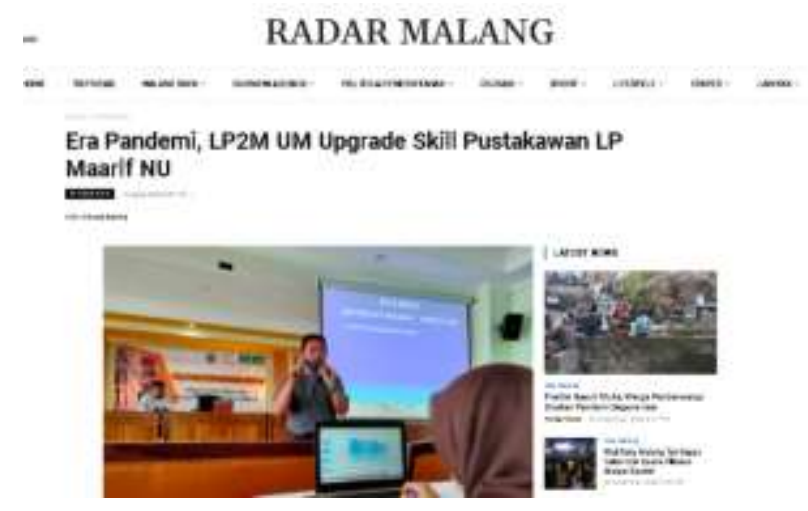

Gambar 17. Terbit pada media online Radar Malang

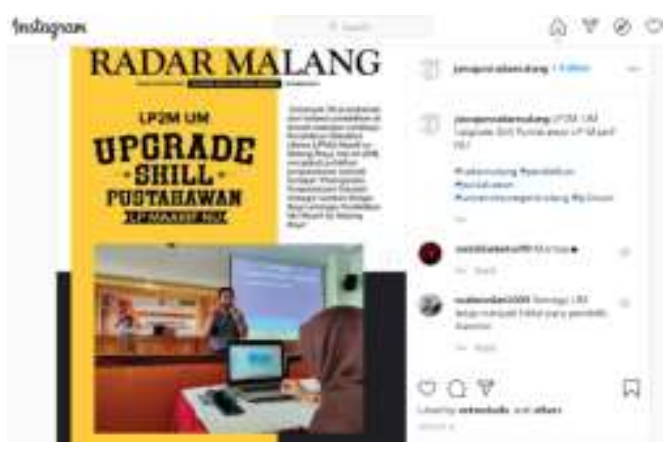

Gambar 18. Publikasi pada Instagram Radar Malang

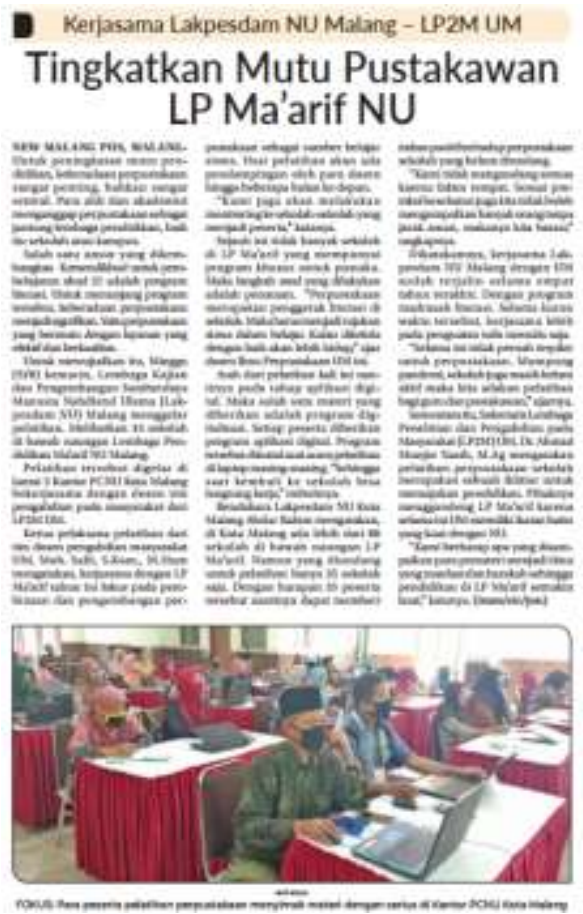

Gambar 19. Liputan Malang Post Edisi Senin 10 Agustus 2020

\subsection{Pembahasan}

a) Penilaian Pre-Test

Evaluasi pengetahuan dasar peserta dilaksanakan awal kegiatan dengan memberikan pre-test untuk dikerjakan oleh peserta. Berdasarkan hasil pre-test didapatkan kesimpulan sebagai berikut;

Tabel 5. Hasil Pre-Test

\begin{tabular}{clcc}
\hline No & Kategori Soal & Rata-rata & Kategori Penilaian \\
\hline 1 & Klasifikasi dan Katalogisasi & 4 & Tidak Baik \\
2 & Manajemen Perpustakaan & 84 & Sangat Memuaskan \\
3 & Otomasi Perpustakaan & 12 & Tidak Baik \\
& Nilai rata-rata & 33 & Sangat Kurang \\
\hline
\end{tabular}

Kategori soal Manajemen Perpustakaan, hampir keseluruhan peserta mampu menjawab dengan baik karena soal yang diberikan terkait dengan Planning, Organizing, Actuating, dan Controlling (POAC). Sehingga secara nalar, tidak kesulitan untuk menjawab. Namun pada bidang inti perpustakaan pada kategori klasifikasi dan katalogisasi serta otomasi perpustakaan, peserta mendapatkan kategori penilaian tidak baik. Ini artinya peserta yang hadir memang belum 
pernah mendapatkan pelatihan perpustakaan sama sekali. Secara keseluruhan dari hasil pre-test mendapatkan kategori penilaian sangat kurang.

b) Penilaian Post-Test

Penilaian akhir ini diberikan menjelang penutupan. Peserta diminta mengakses Google Form berisi soal post-test. Dari proses penilaian didapatkan kesimpulan sebagai berikut

Tabel 6. Hasil Post-Test

\begin{tabular}{cccc}
\hline No & Kategori Soal & Rata-rata & Kategori Penilaian \\
\hline 1 & Klasifikasi dan Katalogisasi & 94 & Sangat Memuaskan \\
2 & Manajemen Perpustakaan & 96 & Sangat Memuaskan \\
3 & Otomasi Perpustakaan & 87 & Sangat Memuaskan \\
& Nilai rata-rata & 92 & Sangat Memuaskan \\
\hline
\end{tabular}

Berdasarkan perbandingan antara nilai pre-test dan post-test didapatkan peningkatan tambahan pengetahuan secara signifikan. Peserta mendapatkan pengetahuan baru terkait pengelolaan perpustakaan sekolah. Materi yang disampaikan selama pelatihan merupakan salah satu dari kompetensi inti pengelola perpustakaan sekolah (Wicaksono, 2018). Sehingga dengan berbekal pelatihan tersebut pustakawan dapat mengelola perpustakaan sesuai kaidah bidang ilmu perpustakaan.

\section{KESIMPULAN}

Pelatihan pengelolaan perpustakaan sekolah telah memberikan manfaat bagi peserta dengan membandingkan peningkatan nilai saat pre-test dengan post-test. Diikuti oleh 35 peserta yang mayoritas belum pernah mengikuti pelatihan perpustakaan sebelumnya. Didapatkan kesimpulan sebagai berikut

a) Penilaian pre-test dengan kategori soal klasifikasi dan katalogisasi, manajemen perpustakaan dan otomasi perpustakaan mendapatkan nilai rata-rata 33 yaitu dengan kategori penilaian sangat kurang.

b) Sedangkan untuk penilaian post-test dengan kategori soal yang sama dengan pre-test didapatkan nilai rata-rata 97, yang masuk dalam kategori sangat memuaskan.

\section{UCAPAN TERIMA KASIH}

Penulis mengucapkan terima kasih kepada LP Maarif Nahdlatul Ulama Kota Malang dan LP2M yang memberikan kesempatan dalam bentuk pendanaan untuk menyelenggarakan pengabdian ini.

\section{DAFTAR PUSTAKA}

Andayani, U. (2018). Strategi pengembangan kompetensi pustakawan akademik sebagai blended librarian dalam penyediaan layanan perpustakaan di era keilmuan digital. In $A L$ MAKTABAH (Vol. 17). Retrieved from http://journal.uinjkt.ac.id/index.php/almaktabah/article/view/11061

Hairun, Y. (2020). Evaluasi dan Penilaian dalam Pembelajaran. Jogjakarya: Deepublish.

Henry Februariyanti, E. Z. (2012). Rancang Bangun Sistem Perpustakaan untuk Jurnal Elektronik. Jurnal Teknologi Informasi DINAMIK.

Loneli Costaner, Guntoro, \& Yuhelmi. (2020). Penerapan Sistem Sirkulasi Perpustakaan Berbasis Slims Pada SMA IT Al Fityah Pekanbaru. Dinamisia : Jurnal Pengabdian Kepada Masyarakat, 4(2), 268-274. https://doi.org/10.31849/dinamisia.v4i2.3926 
Maulida, H. N. (2019). Layanan Pustaka Islam Berbasis Digital. Iqra`: Jurnal Ilmu Perpustakaan Dan Informasi (e-Journal), 13(2), 116. https://doi.org/10.30829/iqra.v13i2.5878

Nugraha, F. (2014). Analisa dan perancangan sistem informasi perpustakaan. Jurnal Teknologi Informasi \& Pendidikan ITP, 3(1), 102-109.

Nurhandini, W. E. (2020). Inovasi Layanan Ruang Baca Anak Di Dinas Perpustakaan Umum Dan Arsip Daerah Kota Malang. In Jurnal Kajian Perpustakaan dan Informasi BIBLIOTIKA : Jurnal Kajian Perpustakaan dan Informasi (Vol. 4). Retrieved from http://journal2.um.ac.id/index.php/bibliotika

Puspitasari, D. (2016). Sistem Informasi Perpustakaan Sekolah Berbasis Web. None.

Vidiyawati, H. (2017). Manajemen layanan perpustakaan di SMA Nahdlatul Ulama 1 Gresik.

Wicaksono, M. F. (2018). Membandingkan Kompetensi Pustakawan Pendidikan dengan Pustakawan Pelatihan. Jurnal Ilmu Informasi, Perpustakaan, Dan Kearsipan, 20(2). https://doi.org/10.7454/jipk.v20i2.103 